Original Research Article

\title{
Geriatric prescription analysis with respect to "STOPP" and "START" criteria: a descriptive study in the Indian scenario
}

\author{
Mangala B. Murthy*, Krishna Jagtap, Shreyas R. Burute, Sunita J. Ramanand, \\ Shraddha M. Pore, Praveenkumar T. Patil
}

Department of Pharmacology, Government Medical College, Pandharpur road, Miraj, Maharashtra, India

Received: 28 September 2017 Accepted: 27 October 2017

*Correspondence to: Dr. Mangala B Murthy, Email: mangala.bhaskar@ gmail.com

Copyright: (C) the author(s), publisher and licensee Medip Academy. This is an openaccess article distributed under the terms of the Creative Commons Attribution NonCommercial License, which permits unrestricted noncommercial use, distribution, and reproduction in any medium, provided the original work is properly cited.

\begin{abstract}
Background: Patients; sixty-five years of age and above, are a special risk group as far as drug prescribing is concerned. Prescription irregularities in such patients may be hazardous. STOPP/START criteria are considered as the most up to-date set of explicit criteria for evaluating geriatric prescriptions. To analyse geriatric prescriptions in a tertiary care centre with respect to STOPP/START criteria and WHO core drug prescribing indicators so as to get an idea of pattern of drug prescription in geriatric patients as well as frequency of potentially inappropriate prescriptions. Descriptive cross-sectional study in a tertiary care hos pital.

Methods: All inpatients aged 65 years and above who were prescribed at least one allopathic medication and consented to participate in the study were included and patients admitted for medical emergencies were excluded. Demographic data and details of drugs prescribed were collected from prescription chits and indoor case papers.

Results: There was a high frequency of polypharmacy, prescription of antimicrobials and injections. Proportion of patients receiving at least one potentially inappropriate medication (PIM) as per STOPP criteria was $21.01 \%$. Proportion of patients subjected to at least one potential prescribing omission (PPO) as per START criteria was $33.33 \%$. Proportion of patients exposed to potentially inappropriate drug prescriptions as a whole (PIPs=PIMs+PPOs) was $46.37 \%$. Statistical analysis used as descriptive statistics like numbers and percentages were used for data analysis.

Conclusions: With regards to geriatric prescribing, adherence to WHO core prescribing indicators, prescription of drugs as per STOPP and START guidelines are indicative of scope for improvement.
\end{abstract}

Keywords: Polypharmacy, START criteria, STOPP criteria

\section{INTRODUCTION}

People above 65 years of age are commonly referred to as geriatric population and they would amount to $10.7 \%$ of total population of India by $2021 .^{1}$ Challenges to the medical fraternity in treating geriatric patients arise from their frail and vulnerable body physique, physiological and pathological changes in their hepatic and renal function and multiple co-morbidities which makes them the highest consumers of prescribed drugs. These factors expose geriatric patients to potentially inappropriate prescriptions (PIP) defined as over use of drugs, irrational choice leading to prescription of a potentially inappropriate medication (PIM) or under use of appropriate drugs leading to a potential prescribing omission(PPO). ${ }^{1}$ PIMs in turn predispose the elderly to a triad of adverse drug reactions, drug-drug and drug- disease interactions. ${ }^{2-5}$ while prescribing omissions (PPOs) fail to provide necessary protection against morbidity and mortality from certain diseases common in the elderly.

There are many criteria to evaluate rationality of drugs prescribed to geriatric patients. Beer's criteria, Phadke's criteria and Screening Tool of Older Person's potentially 
inappropriate Prescriptions (STOPP) and Screening Tool to Alert doctors to the Right Treatment (START) criteria are a few among the list. ${ }^{4-11}$ Beer's criteria, the most popular tool for studies on geriatric prescribing, has limitations like less importance being given to under use of drugs, drug interactions and therapeutic duplication. ${ }^{3}$

On the other hand, STOPP comprises of 80 indicators pertaining primarily to important drug-drug and drugdisease interactions and therapeutic duplication. START incorporates 34 criterion based indicators of prescribing omissions. ${ }^{3}$ STOPP/START criteria are considered as the most up to-date set of explicit criteria for evaluating geriatric prescriptions based on drugs prescribed and disease present and require little clinical judgement, thus suitable for use by researchers, students and clinicians.

The present study was conducted to analyse geriatric prescriptions in a tertiary care centre with respect to STOPP/START criteria and WHO core drug prescribing indicators so as to get an idea of pattern of drug prescription in geriatric patients as well as frequency of potentially inappropriate prescriptions. The above information could be used as a baseline to take corrective measures if found necessary.

\section{METHODS}

\section{Study design, place and duration of the study}

This was a cross-sectional study of 3 months duration conducted in the inpatient departments of a tertiary care centre. All tenets of the Declaration of Helsinki were followed during the study. The study was approved by the institutional ethics committee and informed consent was sought from the patients before enrolment into the study.

\section{Inclusion criteria}

- Patients aged 65 years and above, of either sex, having a prescription for at least one drug prescribed by an allopathic doctor.

- Prescriptions given to inpatients of medicine, surgery, gynecology, ENT, ophthalmology and orthopedics were included in the study.

\section{Exclusion criteria}

- Patients admitted to ICU and patients on ventilators were excluded as in many of these patients, clinical judgment of an individual case may overrule guidelines.

- Patients not willing to participate in the study.

\section{Sample size}

Literature search revealed the frequency of potentially inappropriate prescriptions in geriatric age group to be $42 \%$. Assuming this frequency and allowable error of $20 \%$ of this frequency, a sample of 138 prescriptions were to be screened to achieve the study objectives.

\section{Data collection}

Data was collected from prescription chits, indoor case papers, and also by questioning the patient directly for clarifications wherever required. Pre-structured case record form was used to collect data. Data of demographic parameters like age, gender, was recorded along with disease parameters like diagnosis, concomitant dis eases, drugs prescribed, dose of each drug, route of drug administration, frequency of administration of each drug and duration for which the drug was prescribed.

Analysis of prescriptions of enrolled patients was done as follows:

- Drugs prescribed were classified according to system to which the indication was related. (like $\mathrm{H} 2$ blockers under digestive system, antimicrobials were classified as chemotherapeutic agents in general).

- WHO drug prescribing indicators such as average number of drugs prescribed per prescription and percentage of prescriptions based on generic/brand names, proportion of prescriptions containing at least one antimicrobial, proportion of prescriptions containing injections and proportion of drugs prescribed from national list of essential medicines was calculated.

- STOPP criteria were applied for every drug of the prescription individually and marked as PIM whenever found. Proportion of patients receiving at least one PIM was calculated by dividing total number of prescriptions with at least one PIM by the total number of prescriptions analyzed, multiplied by 100 .

- Similarly START criteria were applied to each prescription to look for omission errors. Proportion of patients subjected to PPOs was calculated by dividing the number of prescriptions with omission errors by total number of prescriptions analyzed, multiplied by 100.

- Proportion of patients exposed to potentially inappropriate prescription as a whole was calculated by adding the number of prescription with at least one PIPs due to either STOPP and/or START criteria and diving it by the total number of prescriptions analyzed multiplied by 100 .

- To study the potential implications of the above potentially inappropriate prescriptions.

Statistical analysis as descriptive statistics like numbers and percentages were used for data analysis.

\section{RESULTS}

A total of 138 prescriptions were included in the study and the pre-calculated sample size was achieved. Geriatric patients whose prescriptions were studied ranged from 65 years to 95 years. The mean age of these patients was 71.72 
years, $75(54.34 \%)$ were males and $63(45.65 \%)$ were females (Table 1).

Table 1: Demographic characteristics of patients to whom prescriptions under study were issued.

\begin{tabular}{|ll|}
\hline $\begin{array}{l}\text { Demographic } \\
\text { parameter }\end{array}$ & $\begin{array}{l}\text { Number of patients }(\%) \\
\mathbf{N}=\mathbf{1 3 8}\end{array}$ \\
\hline Age in years & \\
\hline Range & $65-95$ years. \\
\hline Mean age & $71.72 \pm 6.80$ years. \\
\hline$\geq 65$ years & 106 \\
\hline$\geq 75$ years & 22 \\
\hline$\geq 85$ years & 8 \\
\hline$\geq 95$ years & 2 \\
\hline Total & $138(100 \%)$ \\
\hline Gender & $75(54.34 \%)$ \\
\hline Males & $63(45.65 \%)$ \\
\hline Females & $138(100 \%)$ \\
\hline Total &
\end{tabular}

Total number of drugs prescribed to the patients in 138 prescriptions amounted to 958. Most commonly prescribed drugs were from cardiovascular system and chemotherapeutic agents ( $22 \%$ each). Others were drugs from gastrointes tinal system, respiratory system, endocrine systemand multivitamins (Table 2).

Table 2: Distribution of drugs prescribed according to the organ system to which they belong.

\begin{tabular}{|ll|}
\hline Organ system & Number (\%) \\
\hline Cardiovascular system & $217(22.65 \%)$ \\
\hline Antimicrobials & $213(22.23)$ \\
\hline Gastrointestinal system & $181(18.89 \%)$ \\
\hline Multivitamins & $93(9.70 \%)$ \\
\hline Respiratory system & $69(7.20 \%)$ \\
\hline Musculoskeletal system & $45(4.69 \%)$ \\
\hline Immunosuppressant & $41(4.27 \%)$ \\
\hline Endocrine and metabolic disorders & $25(2.60 \%)$ \\
\hline Iron preparations & $17(1.77 \%)$ \\
\hline Enzymes & $17(1.77 \%)$ \\
\hline Central nervous system & $16(1.67 \%)$ \\
\hline Genitourinary disorders & $8(0.83 \%)$ \\
\hline Others & $16(1.67 \%)$ \\
\hline Total & 958 \\
\hline
\end{tabular}

Each prescription contained $6.94 \pm 2.11$ drugs on an average. Out of 958 drugs prescribed, very few drugs (ie. $261 / 958,27.24 \%$ ) were prescribed by generic name and as high as $72.75 \%$ were prescribed as brand name. $92.37 \%$ of the prescribed drugs belonged to NLEM. A high percentage of prescriptions contained at least one antimicrobial $(82.60 \%)$ prescribed and $70.28 \%$ had at least one injection (Table 3 ).

Out of 138 prescriptions that were analyzed for prescribing errors in elderly as per both STOPP/START criteria,
$46.37 \%$ of the prescriptions had at least one error either as per STOPP or START criteria. Considering STOP and START criteria separately, proportion of patients receiving prescriptions with at least one potentially inappropriate medication prescribed as per STOPP criteria was $21.01 \%$ while proportion of patients receiving a prescription with potential prescribing omission as per START criteria was $33.33 \%$ (Table 4).

Table 3: Analysis of prescriptions according to WHO core prescribing indicators.

\begin{tabular}{|ll|}
\hline WHO core prescribing indicator & Number (\%) \\
\hline $\begin{array}{l}\text { Average number of drugs per } \\
\text { prescription }\end{array}$ & $6.94 \pm 2.11$ \\
\hline Drugs prescribed by generic name & $261(27.24 \%)$ \\
\hline Drugs prescribed by brand name & $697(72.75 \%)$ \\
\hline $\begin{array}{l}\text { Drugs prescribed from National list } \\
\text { of essential medicines. (NLEM) }\end{array}$ & $885(92.37 \%)$ \\
\hline Prescriptions with antimicrobials & $114(82.60 \%)$ \\
\hline Prescriptions with injections & $97(70.28 \%)$ \\
\hline
\end{tabular}

Table 4: Tally of potentially inappropriate prescriptions as per STOPP and START criteria.

\begin{tabular}{|c|c|}
\hline Prescription Characteristic & $\begin{array}{l}\text { Number or } \\
\text { percentage of } \\
\text { prescriptions with } \\
\text { the said } \\
\text { characteristic } \\
n=138\end{array}$ \\
\hline $\begin{array}{l}\text { Number of prescriptions } \\
\text { analyzed }\end{array}$ & 138 \\
\hline $\begin{array}{l}\text { Number of prescriptions with at } \\
\text { least one PIM (potentially } \\
\text { inappropriate medication) } \\
\text { prescribed as per STOPP } \\
\text { criteria }\end{array}$ & 29 \\
\hline $\begin{array}{l}\text { Proportion of patients receiving } \\
\text { a prescription with at least one } \\
\text { PIM }\end{array}$ & $21.01 \%$ \\
\hline $\begin{array}{l}\text { Total number of PIMs as per } \\
\text { STOPP criteria }\end{array}$ & 29 \\
\hline $\begin{array}{l}\text { Number of prescriptions with at } \\
\text { least one POP (potentially } \\
\text { prescribing omission) as per } \\
\text { START criteria }\end{array}$ & 46 \\
\hline $\begin{array}{l}\text { Proportion of patients receiving } \\
\text { a prescription with at least one } \\
\text { PPO }\end{array}$ & $33.33 \%$ \\
\hline $\begin{array}{l}\text { Total number of POPs as per } \\
\text { START criteria }\end{array}$ & $61 *$ \\
\hline $\begin{array}{l}\text { Total number of prescriptions } \\
\text { with at least one PIP (either as } \\
\text { per STOPP or START criteria) }\end{array}$ & 64 \\
\hline $\begin{array}{l}\text { Proportion of patients receiving } \\
\text { a PIP as per either of the criteria }\end{array}$ & $46.37 \%$ \\
\hline
\end{tabular}


There were 46 prescriptions with at least one prescribing omission out of which, 31 prescriptions had only one PPO while 15 prescriptions have 2 PPOs as per START criteria. Application of STOPP criteria to 138 prescriptions resulted in 29 PIMs. The most common potentially inappropriate medications prescribed were NSAIDs for long term pain relief in osteoarthritis, NSAIDs for patients of severe hypertension, and loop diuretics prescribed as first line antihypertensive drugs. Others included concomitant use two drugs that increase anticholinergic drug burden and therapeutic duplications like prescription of the same drug by two routes in the same patient. One patient was prescribed long term aspirin at a dose higher than maximu $\mathrm{m}$ recommended dose of $160 \mathrm{mg} /$ day (Table 5).

\section{Table 5: Subgroup analysis of PIMs as per STOPP criteria.}

\begin{tabular}{|c|c|c|}
\hline $\begin{array}{l}\text { Drug category as per STOPP } \\
\text { criteria }\end{array}$ & Type of STOPP criteria to which prescribing error was attributed & Number \\
\hline \multirow[b]{2}{*}{ Cardiovascular system } & Loop diuretics as first line treatment of hypertension & 4 \\
\hline & $\begin{array}{l}\text { Sildenafil prescribed concurrently for a patient of angina on treatment } \\
\text { with nitrates. }\end{array}$ & 1 \\
\hline $\begin{array}{l}\text { Anti-platelet-anticoagulant } \\
\text { drugs }\end{array}$ & Long term treatment with aspirin dose greater than $160 \mathrm{mg} / \mathrm{day}$. & 1 \\
\hline \multirow{3}{*}{ Musculoskeletal system } & NSAID prescribed long term for a patient of severe hypertension & 5 \\
\hline & NSAID prescribed for a patient of severe heart failure & 2 \\
\hline & Long term NASIDs for pain relief in osteoarthritis as first line therapy & 8 \\
\hline $\begin{array}{l}\text { Antimuscarinic/ Anticholinergic } \\
\text { drug }\end{array}$ & $\begin{array}{l}\text { Concomitant use of two drugs with antimuscarinic property- } \\
\text { Intestinal antis pasmodic with first generation antihistaminic }\end{array}$ & 3 \\
\hline \multirow{3}{*}{ Therapeutic duplication } & 2 third generation cephalos porins prescribed together & 2 \\
\hline & Two NSAIDs prescribed together & 2 \\
\hline & $\mathrm{H} 2$ blocker in the same patient prescribed by both routes - iv and oral & 1 \\
\hline Total number of PIMs & & 29 \\
\hline
\end{tabular}

Table 6: Subgroup analysis of PIMs as per START criteria.

\begin{tabular}{|c|c|c|}
\hline $\begin{array}{l}\text { Drug category as } \\
\text { per START criteria }\end{array}$ & Type of START criteria to which prescribing error was attributed & Number \\
\hline \multirow{7}{*}{ CVS } & $\begin{array}{l}\text { Antiplatelet therapy with a documented history of coronary, cerebral or peripheral } \\
\text { vascular disease. }\end{array}$ & 5 \\
\hline & $\begin{array}{l}\text { Statin therapy with a documented history of coronary, cerebral or peripheral } \\
\text { vascular disease, unless the patient's status is end-of-life or age is }>85 \text { years. }\end{array}$ & 11 \\
\hline & ACE inhibitor in systolic heart failure. & 10 \\
\hline & Appropriate beta-blocker with stable systolic heart failure. & 2 \\
\hline & Beta-blocker with ischaemic heart disease & 6 \\
\hline & $\begin{array}{l}\text { Antihypertensive therapy where systolic blood pressure consistently }>160 \mathrm{mmHg} \\
\text { and/or diastolic blood pressure consistently }>90 \mathrm{mmHg} ; 0 \mathrm{r}>140 / 90 \text { if diabetic. }\end{array}$ & 8 \\
\hline & Atrial fibrillation not prescribed warfarin/as pirin. & 2 \\
\hline \multirow[t]{2}{*}{ Respiratory system } & $\begin{array}{l}\text { Regular inhaled beta- } 2 \text { agonist or antimuscarinic bronchodilator (e.g. ipratropium, } \\
\text { tiotropium) for mild to moderate asthma or COPD. }\end{array}$ & 3 \\
\hline & Regular inhaled corticosteroid for moderate-severe asthma or COPD & 9 \\
\hline \multirow{2}{*}{$\begin{array}{l}\text { Musculoskeletal } \\
\text { system }\end{array}$} & $\begin{array}{l}\text { Vitamin D and calcium supplement in patients with known osteoporosis and/or } \\
\text { previous fragility fracture }\end{array}$ & 2 \\
\hline & $\begin{array}{l}\text { Bisphosphonates and vitamin D and calcium in patients taking long-term systemic } \\
\text { corticosteroid therapy. }\end{array}$ & 3 \\
\hline Total & $\begin{array}{lll}2 & 2 & 2 \\
\end{array}$ & \\
\hline
\end{tabular}

Similarly, application of START criteria to the prescriptions under study, showed 61 incidences of prescribing omissions. A high frequency of POPs was related to the cardiovascular system. Omission of ACE inhibitors/ARBs from therapeutic regime of patients with heart failure, betablockers from patients with ischemic heart disease, statins from patients with established coronary, cerebrovascular disease were common. Prescribing omissions in the respiratory diseases were due to lack of long term corticosteroid use in patients of severe 
bronchial asthma. PPO of vitamin D, calcium supplements and bisphosphonates from therapy offered to patients of osteoporosis was also seen (Table 6).

\section{DISCUSSION}

Geriatric age group is a special risk group with respect to drug prescribing. Rationalizing drug prescriptions in geriatric patients is a complicated task requiring a multistep approach like - prior assessment of drug prescribing pattern in the existing setup, identifying problem areas and suggesting interventions to improve prescribing pattern. This has to be followed by repeated mop up rounds to maintain rational prescribing in elderly. As a first step to this approach, analyzing the prescriptions for existing pattern of prescribing in the elderly and adherence to WHO core prescribing indicators was done.

Existing prescription pattern in the elderly shows a high utilization of drugs related to the cardiovascular system and antimicrobials in our set up. This is in concordance with studies conducted in India where 3 most commonly used drug classes belong to cardiovascular system, gastrointestinal system and antimicrobials. ${ }^{12,13}$ Studies conducted in other developing countries like Nigeria also show an increased tendency towards prescription of drugs related to cardiovascular system. WHO core prescribing indicators include elements like average number of drugs per prescription, proportion of prescriptions containing antibiotics, injections, proportion of drugs prescribed by generic name and from national list of essentialmedicines (NLEM). This is a set of basic minimum standard to which prescriptions in a setup should adhere to. In the present study, all the WHO drug prescribing indicators were found to be discordant with the standards recommended by WHO. Although, these prescribing indicators are basically meant to gauge rational prescribing in an OPD setup, it has been used by many tertiary care centres to evaluate rational prescribing practices in their hos pital inpatient department. WHO core prescribing indicators in the present study fall within the range of WHO prescribing indicators as assessed in inpatient departments in various studies. Average number of drugs prescribed per patient in the present study was 6 and this is similar to study conducted by Mushira Taskeen at Hyderabad. ${ }^{14}$ Other studies have averages between 5.5 to 9.6 drugs prescribed to geriatric patients. This confirms to the findings that polypharmacy is rampant in geriatric patients. There was also an increased tendency towards prescription of antimicrobials, injections and prescribing brand names. These findings were also similar to other studies conducted on geriatric patients in India. ${ }^{12,13,15}$

Polypharmacy in the elderly is a result of multiple comorbidities like hypertension, diabetes, heart failure and their complications. However, polypharmacy can also have adverse consequences in the elderly leading to prescribing cascade. Prescribing cascade is misrepresentation of the adverse effects, drug-drug interactions or drug disease interactions as a disease symptom leading to prescription of another drug to treat it. This further complicates the picture of polypharmacy. Continuous medication reviews to reduce number and frequency of medications in elderly could serve as a remedial step in reducing polypharmacy.

Next step was to identify problem areas in geriatric prescribing. This was done by analyzing the prescriptions to identify prescription of any inappropriate medication (PIM) as per STOPP criteria and prescribing omission(PPO) as per START criteria. Proportion of patients subjected to at least one inappropriate medication, prescribing omission or either of them (PIP) as a whole was assessed. In the present study it was observed that $21 \%$ patients were subjected to a potentially harmful medication (PIM). Study conducted in Ireland showed proportion of patients receiving PIM to be $14 \%$, while a study from Australia showed a prevalence of $37.5 \% .{ }^{15,16} \mathrm{It}$ was as high as $51 \%$ in a study conducted by Delleur. ${ }^{17} \mathrm{~A}$ study conducted by Gallenger reports the proportion on PIMs to be between 12-40\% and the results of the present study falls between the same range. ${ }^{18}$ Thus, studies conducted all over the world on geriatric patients have shown wide variations with respect to this parameter. Reason for variation may be due to conduct of study in different settings like outpatient departments, primary care settings or hospitalbased settings and it is well known that prescription of PIMs tends to be higher in hos pital based settings as compared to PIMs reported in community studies. Considering the type of drug prescribed inappropriately in geriatric patients as per STOPP criteria, prescription of long term NSAIDs as first line treatment of osteoarthritis, long term NSAIDs to patients of hypertension and heart failure, prescription of loop diuretics as first line antihypertensive and therapeutic duplications were some of the commonly encountered PIMs in the present study. Study published in European Journal of pharmacology shows prescription of NSAIDs in patients of hypertension as a common PIM while studies analyzing prescriptions as per Beers criteria show common PIMs related to prescription of antihistaminic, muscle relaxants and long acting benzodiazepines.16-19 Thus, criteria adopted for identification of PIMs play a very important role in explaining the discrepancies between studies in this regard. Other explanations for differences in the type of PIPs reported from studies conducted in different geographical areas may be related to the epidemiology of diseases treated in a particular area, local availability of drugs, cost and treatments guidelines followed in a particular setup. Potential implications of PIMs prescribed in our study could be worsening of hypertension and heart failure when NSAIDs are prescribed to patients with these diseases, prescription of aspirin beyond $150 \mathrm{mg} /$ day could lead to higher incidences of gastric bleeding in the elderly, concomitant prescription of drugs with anticholinergic action leads to atropinic side effects like glaucoma, dryness of mouth, retention of urine in patients with benign prostatic hypertrophy and constipation. First line use of NSAIDs instead of paracetamol for long term treatment of osteoarthritis is not 
advisable in the elderly as it can lead to occult blood loss and analgesic nephropathy. Loop diuretics are not to be chosen as first line treatment of hypertension as better drugs in terms of efficacy and tolerability for hypertension are available. Concomitant prescription of sildenafil and nitrates in the elderly may cause dangerous hypotension.

Considering the START criteria for potential prescribing omissions (PPOs), it was found that proportion of patients exposed to PPOs in the present study was 33.33\%. Most common instances of underutilization included ACE inhibitors in patients of heart failure, statins in patients with evidence of cerebral, coronary or peripheral vascular disease, Antihypertensive therapy where systolic blood pressure consistently $>160 \mathrm{mmHg}$ and/or diastolic blood pressure consistently $>90 \mathrm{mmHg}$; Or $>140 / 90$ if diabetic, vitamin $\mathrm{D}$ and calcium supplement in patients with known osteoporosis and/or previous fragility fracture, antiplatelet therapy in the presence of coronary cerebral vascular disease betablockers for stable angina, regular inhaled corticosteroid for moderate-severe asthma or COPD. These results were similar to a study conducted by Pyszka LL. ${ }^{20}$ The potential implications of underutilization of antihypertensives, ACE inhibitors and statins and betablockers for the above said indications reduce the survival benefit offered by these drugs and increase mortality and morbidity form cardiovascular disorders. Underutilization of regular inhaled corticosteroids increase the exacerbation of acute asthma further leading to hospitalizations and underutilization of drugs that increase bone mineral density in patients of osteoporosis increase the incidence of fractures in the elderly. Considering proportion of patients exposed to errors of prescribing as a whole (either a PIM or PPO), it was found that $46 \%$ of the elderly were exposed to one of these errors of prescribing. In fact, errors due to omis sion were 1.6 times more as errors due to commission. A study conducted by Galvin in Europe also showed that errors due to omission were more than errors due to commission although the actual proportion of errors were less in this European study as compared to our study (14\% PIM and 30\% PPO vs 21\%PIM and $33.33 \%$ PPO in our study).

\section{CONCLUSION}

To summarize, with regards to geriatric prescribing, adherence to WHO core prescribing indicators, prescription of drugs as per STOPP and START guidelines are indicative of a scope for improvement in the present setup. Sensitization of prescribers with res pect to the above aspects of geriatric prescribing, encouraging consideration of elderly as a special risk group and emphasis on these aspects of prescribing in teaching curriculum may bring down the discrepancies in geriatric prescribing to an acceptable level. Actual as sessment of the extent to which observed deficiencies in prescribing practices led to clinically observable adverse events was not done in the present study. Further studies to actually assess the clinical implications of inappropriate prescribing have to be conducted to evaluate the health as well as economic consequences of inappropriate prescribing in the geriatric population.

Funding: No funding sources

Conflict of interest: None declared

Ethical approval: The study was approved by the Institutional Ethics Committee

\section{REFERENCES}

1. Chitra B, Senthilvel N, Sowmya R, Sathyan S and Srisha R: A Study on Prescribing Pattern of Drugs in Geriatrics Using Beers Criteria at a Private Corporate Hospital. Int J Pharm Sci Res. 2015;6(11):4810-25.

2. Grodzicki BK, Boparai MK, Lichtman SM. Prescribing for Older Patients with Cancer. Clinical Advances in Hematology \& Oncology. 2014;12:30918.

3. Spinewine A, Schmader KE, Barber N, Hughes C, Lapane KL, Swine C, et al. Appropriate prescribing in elderly people: how well can it be measured and optimised?. Lancet. 2007;370:173-84.

4. Karandikar YS. Measuring inappropriate prescriptions in geriatric population\&58; Overview of various screening tools. International Journal of Medical Research and Health Sciences. 2013;2(3):636-42.

5. Katzung BG. Special aspects of geriatric pharmacology. Trevor, Anthony J, Bertram G Katzung. Basic and clinical pharmacology. $13^{\text {th }}$ Ed. New York: McGraw Hill, Medical; 2015.

6. Rognstad S, Brekke M, Fetveit A, Spigset O, Wyller TB, Straand J. The Norwegian General Practice (NORGEP) criteria for assessing potentially inappropriate prescriptions to elderly patients: a modified Delphi study. Scandinavian journal of primary health care. 2009;27(3):153-9.

7. Marriott J, Stehlik P. A critical analys is of the methods used to develop explicit clinical criteria for use in older people. Age and Ageing. 2012;41:441-50.

8. Kashyap M, Iqbal MZ. A review of screening tools used for the assessment of appropriateness of prescription's among elderly patients. Journal of Pharmaceutical and Biomed Sciences. 2014:72-9.

9. Shah RB, Gajjar BM, Desai SV. Evaluation of the appropriateness of prescribing in geriatric patients using Beers criteria and Phadke's criteria and comparison thereof. $\mathrm{J}$ of Pharmacology \& Pharmacotherapeutics. 2011;2(4):248.

10. Joseph S, Verghese N, Thomas L. A study on prescribing pattern of antihypertensive medications in a tertiary care hospital in Malabar region. Der Pharmacia Lettre. 2014;6(4):132-7.

11. O'Mahony D, Gallagher P, Ryan C, Byrne S, Hamilton H, Barry P, et al. STOPP \& START criteria: a new approach to detecting potentially inappropriate prescribing in old age. European Geriatric Medicine. 2010;1(1):45-51.

12. Sharma N, Advani U, kulshreshtha S, Parakh R, Bansal A, Sinha RR. Screening of prescriptions in geriatric population in a tertiary care teaching hospital 
in north India. The $\mathbf{J}$ of Phytopharmacology. 2013;2(5):38-45

13. Jhaveri BN, Tejas KP, Barvaliya MJ, Tripath CB. Drug utilization pattern and pharmacoeconomic analysis in geriatric medical in-patients of a tertiary care hospital of India. J Pharmacol Pharmacother. 2014;5(1):15-20.

14. Taskeen M, Anitha N, Ali SR, Bharath R, Khan AB. A study on rational drug prescribing pattern in geriatric patients in Hyderabad metropolitan. Journal of Drug Delivery and Therapeutics. 2012;2(5).

15. Jafrin AL, Kumar P, Udhayalakshmi T, Jayapriya B, Sawadkar MS. Drug utilization patterns of Geriatric patients admitted in the Medicine Department of a Tertiary Care Hospital. International J of Pharmacy \& Life Sciences. 2013;4(11).

16. Galvin R, Moriarty F, Cousins G, Cahir C, Motterlini $N$, Bradley $M$, et al. Prevalence of potentially inappropriate prescribing and prescribing omis sions in older Irish adults: findings from The Irish LongituDinal Study on Ageing study (TILDA). Eur J Clin Pharmacol. 2014;70(5):599-606.

17. Dalleur O, Spinewine A, Henrard S, Losseau C, Speybroeck N, Boland B. Inappropriate prescribing and related hospital admissions in frail older persons according to the STOPP and START criteria. Drugs Aging. 2012;29(10):829-37.

18. Gallagher P, Ryan C, Byrne S, Kennedy J, O'Mahony D. STOPP (Screening Tool of Older Person's Prescriptions) and START (Screening Tool to Alert doctors to Right Treatment). Consensus validation. International journal of clinical pharmacology and therapeutics. 2008;46(2):72-83.

19. Lai HY, Hwang SJ, Chen YC, Chen TJ, Lin MH, Chen LK. Prevalence of the prescribing of potentially inappropriate medications at ambulatory care visits by elderly patients covered by the Taiwanese National Health Insurance program. Clin Ther. 2009;31(8):1859-70.

20. Pyszka LL, Seys Ranola TM, Milhans SM. Identification of inappropriate prescribing in geriatrics at a Veterans Affairs hospital using STOPP/START screening tools. Consult Pharm. 2010;25(6):365-73

Cite this article as: Murthy MB, Jagtap K, Burute SR, Ramanand SJ, Pore SM, Patil PT. Geriatric prescription analysis with respect to "STOPP" and "START" criteria: a descriptive study in the Indian scenario. Int J Basic Clin Pharmacol 2017;6:2864-70. 